
\title{
R Research S Surare \\ Quality Evaluation in Delivering Care of Acute Myocardial Infarction in Sancti-spirítus, Cuba
}

Miguel Alejandro Rodriguez-Ramos ( $\nabla$ mialero@infomed.sld.cu )

Hospital Provincial Universitario Camilo Cienfuegos https://orcid.org/0000-0003-0689-9216

Gilberto Cairo-Saez

Policlinico Universitario Marta Abreu

Juan Antonio Prohias-Martinez

CardioCentro Hermanos Ameijeiras, Hospital Hermanos Ameijeiras

Research article

Keywords: quality of care, performance measures, Acute Myocardial Infarction, low/middle income country, low/middle income setting, low/middle income scenario

Posted Date: June 15th, 2020

DOI: https://doi.org/10.21203/rs.3.rs-33820/v1

License: @ (i) This work is licensed under a Creative Commons Attribution 4.0 International License.

Read Full License 


\section{Abstract}

Background: Prevalence of cardiac conditions is increasing worldwide. Low and middle-income scenario (LMISs), especially in Latin America, don't scape from this phenomenon. To give a high-quality cardiovascular disease care may be economic challenging for these countries, in every level of attention.

Methods: Observational and retrospective study of quality of care evaluation using the European Society of Cardiology (ESC 2017) Quality of Care Working Group's consensus on quality document, of admitted Acute Myocardial Infarction in a General Hospital in Sancti-Spiritus, Cuba.

Results: Between 2017 and 2019, 660 patients with AMI were admitted, most of them (72\%), presented with features of ST-elevation myocardial infarction. Thrombolytics were administered to $268(72.4 \%)$ patients, $43(16 \%)$ of them in less than 30 minutes after diagnosis. Double antiplatelet treatment was administered to $98.1 \%$ of patients at admission. However, only 163 (34.8\%) were enrolled in secondary prevention programs. No information regarding Patient Experience, nor 30-day adjusted mortality, was collected. Secondary prevention was fulfilled around $90 \%$

Conclusion: Determination of the quality metrics brought some improvement for the perception of the actual quality of care in this low/middle income scenario. Pre-hospital quality markers need to be improved, before trying to introduce a higher level of treatment.

\section{Key Messages}

- What is already known about this subject? Guidelines of attention of Acute Myocardial Infarction recently included updated set of performance measures. As this document comes from a very different setting, it is not clear, for low/middle income scenarios, how achievable are this quality markers. This gaps on attention may generate an excess mortality and morbidity associated to poor quality of care for cardiovascular disease in Latin America, which haven't been assessed either.

- What does this study add? This evaluation, with inherited limitations, set a basis for measure quality of care in a low/middle income scenario, a non-interventional center, with free of charge and universal access to state funded-health care system, with a set of performance measures suggested in recognized international guidelines. This work creates a basis, to include evaluation of performance in care of cardiovascular diseases a daily practice in a center of LMIS, despite been fulfilled or not, a common feature of resource-limited units.

- How might this impact on clinical practice? By identifying gaps in attention, protocols may be updated to correct disparities founded. This quality intervention should be assessed again, to create a new evidence, which may indicate if changes addressed where enough. Results described are a start-line to verify, and compare new assessment of quality metrics.

\section{Background}


Prevalence of cardiac conditions is increasing worldwide ${ }^{1}$. This increase has made of them, a major cause of death ${ }^{2}$. LMISs, especially in Latin America, don't scape from this phenomenon ${ }^{3}$. So, it is imperative to improve cardiovascular disease care to achieve a high-quality standard ${ }^{4}$. One of the most common cardiac condition, that requires intensive care, is AMI. To assess the quality of care provided to patient with this condition may influence their final outcome.

To give a high-quality cardiovascular disease care may be economic challenging for these countries, in every level of attention ${ }^{5}$. In Cuba, patients have free of charge universal access to state-funded health care, with no private practices ${ }^{6}$. And, in the case of AMI is not different. There, in $110000 \mathrm{~km}^{2}$ and 11 millions inhabitants, are three well established regional networks, leaded by a tertiary center where coronary interventions (on hours) and cardiac surgery take place.

Yet, AMI attention is mostly provided in general hospitals, which are the leaders of the state network. These centers are responsible for short, middle and long-term assistance of most cases; they also stratify patients to select which of them most be sent to a tertiary center for interventionist procedures.

No clinical guideline or quality metrics of attention have been published yet. Despite data regarding number of patients and treatment is collected by statistics system, official publication of them is lacking ${ }^{7}$. So, comparison of results from different institutions is difficult for health care providers.

Identification in gaps of attention may led to a better care. In General Hospital "Camilo Cienfuegos" in Sancti Spiritus, Cuba, a digital system with continuous evaluation of care was established ${ }^{8}$, with several improvements after updating its protocols. Current research in this particular topic includes evaluation of performance measures, and creation of set of specific quality markers for our settings.

\section{AIM}

This paper evaluates the quality of care for patients admitted with AMI in a secondary general hospital in Sancti-Spirítus, Cuba, a low/middle-income scenario.

\section{Methods}

\section{Study Design and Selection of quality indicators}

Observational and retrospective study of quality of care evaluation using the European Society of Cardiology Quality of Care Working Group's consensus on quality document ${ }^{9}$. It was selected this time, as the framework for evaluation. This document provides a series of metrics distributed in eight domains: regarding to organization of network, reperfusion therapy, risk assessment, in-hospital anti-thrombotic treatment, discharge medication, patient-reported outcomes, outcomes measures, and composite QI.

\section{Data collection and population}


This study uses an implemented electronic AMI registry, co-designed by cardiologists of General Hospital Camilo Cienfuegos and a software's engineer of DESOFT ${ }^{10}$. The main intention was to create a tool to allow systematic evaluation of care for patients with AMI.

Data pertaining to patient characteristics, history, diagnosis, management and in-hospital outcomes, including lab results, for all AMI admitted in Coronary Intensive Care Unit of General Hospital Camilo Cienfuegos of Sancti-Spiritus (CUBA), in any moment of their in-hospital evolution, with available information of QI based on European Society of Cardiology 2017 Quality of Care Working Group's markers, were included, despite thrombolytic approach, or in-hospital outcome. To avoid missing data, some parameters are necessary to fill, in order to include patients in the database; system warns if one of these is missing.

\section{Analysis}

Data collected from RESCUE study were transferred into Statistical Package for Social Sciences (SPSS, version 24, IBM, Armonk, New York), which was used for data cleaning, management, and analyses. Categorical variables are presented as number and percentage, and continuous variables as mean and standard deviation.

Structural data, and internal protocols (Domain 1) will be further discussed. Compliance was reported as a percentage of the eligible population, and for Domain 5 (secondary prevention discharge treatment), compliance with prescription of treatment will be addressed only with patients who were discharged alive, as previously reported.

The study was conducted in full conformance with principles of Declaration of Helsinki. Ethical approval for the study was obtained from the Institutional Scientific Committee, in its regular meeting on January $14^{\text {th }}, 2020$.

Nor patients, nor the public were involved in the design of this study.

\section{Setting}

This evaluation comes from patients between 2017 and 2019 of the REgistro de Sindromes Coronarios AgUdos [Registry of Acute Coronary Syndrome (RESCUE)] at General Hospital Camilo Cienfuegos, SanctiSpirítus,; a Cuban medical center lacking on-site percutaneous coronary intervention (PCl), which also lacks the capacity to transfer its patients to a $\mathrm{PCl}$ center.

\section{Results}

\section{Demographics, risk factors and clinical presentation}

Between 2017 and 2019, 660 patients with AMI presented to Coronary Intensive Care Unit of General Hospital Camilo Cienfuegos of Sancti-Spirítus (CUBA). The majority of patients, 475 (72\%) admitted 
through the registry presented with features of STEMI. Mean age was 66.6 years $( \pm 12.1)$ and $443(67.1 \%)$ were male.

On admission 87 (13.2\%) patients had a Killip classification of heart failure of $>1$.

Clinical presentation and the prevalence of comorbidities and other risk factors for AMI are described in Table 1. 
Table 1

Baseline characteristics of studied population

\begin{tabular}{|c|c|c|c|}
\hline Parameters & $\begin{array}{l}\mathrm{N}: 660 \\
\text { patients }\end{array}$ & (Cont) & $\begin{array}{l}\mathrm{N}: 660 \\
\text { patients }\end{array}$ \\
\hline Age years $\pm S D$ & $66.4 \pm 12$ & TIMI score at admission \pm SD & $2.7 \pm 1.2$ \\
\hline STEMI patients (\%) & $475(72)$ & CRUSADE score at admission \pm SD & $37.2 \pm 15$ \\
\hline Female gender (\%) & $217(32.9)$ & Cardiogenic shock $(\%) \pm S D$ & $42(7.7)$ \\
\hline Diabetes Mellitus type $2(\%)$ & $190(28.8)$ & Killip class $\geq 2(\%)$ & $142(21.5)$ \\
\hline Hypertension (\%) & $569(86.2)$ & Anterior Myocardial Infarction (\%) & 34652.4 \\
\hline Known CAD (\%) & $243(36.8)$ & Total ischemic time $(\min \pm S D$ & $319 \pm 300$ \\
\hline Prior Myocardial Infarction & $101(15.3)$ & $\begin{array}{l}\text { Aspirin in } 12 \mathrm{~h} \text { after symptoms onset } \\
(\%)\end{array}$ & $608(92.1)$ \\
\hline Prior Stroke (\%) & $21(3.2)$ & ADPI in $12 \mathrm{~h}$ after symptoms onset (\%) & $610(92.4)$ \\
\hline Peripheral artery diseases (\%) & $26(3.9)$ & Statins at admission (\%) & $659(99.8)$ \\
\hline Dyslipidemia (\%) & $40(6.1)$ & Betablockers at admission (\%) & $520(78.8)$ \\
\hline Atrial Fibrillation (\%) & $12(1.8)$ & ACE inhibitors at admission (\%) & $608(92.1)$ \\
\hline Congestive heart failure (\%) & $15(2.3)$ & Diuretics at admission (\%) & $122(18.5)$ \\
\hline Current smoking (\%) & $336(50.9)$ & Streptokinase administration (\%) & $276(58.1)$ \\
\hline $\begin{array}{l}\text { Left Ventricle Ejection Fraction } \\
\text { (in \%) } \pm \text { SD }\end{array}$ & $47.3 \pm 8.7$ & $\begin{array}{l}\text { Aspirin at discharge (\% from } \\
\text { discharged alive) }\end{array}$ & $594(97.4)$ \\
\hline $\mathrm{eGFR}(\mathrm{MDRD}, \mathrm{ml} / \mathrm{min}) \pm \mathrm{SD}$ & $\begin{array}{l}66.3 \pm \\
25.6\end{array}$ & $\begin{array}{l}\text { ADPI at discharge (\%from discharged } \\
\text { alive) }\end{array}$ & $585(95.9)$ \\
\hline Glycaemia $(\mathrm{mmol} / \mathrm{L}) \pm \mathrm{SD}$ & $7.4 \pm 4$ & $\begin{array}{l}\text { Statins at discharge (\%from } \\
\text { discharged alive) }\end{array}$ & $597(97.9)$ \\
\hline Cholesterol $(\mathrm{mmol} / \mathrm{L}) \pm \mathrm{SD}$ & $4.9 \pm 1.2$ & $\begin{array}{l}\text { Betablockers at discharge (\% from } \\
\text { discharged alive) }\end{array}$ & $535(87.7)$ \\
\hline Total CK $(\mathrm{UI} / \mathrm{L}) \pm \mathrm{SD}$ & $\begin{array}{l}809.3 \pm \\
715\end{array}$ & $\begin{array}{l}\text { ACE inhibitors at discharge (\% from } \\
\text { discharged alive) }\end{array}$ & $593(97.2)$ \\
\hline CK-MB (UI/L) $\pm S D$ & $\begin{array}{l}147.9 \pm \\
136\end{array}$ & $\begin{array}{l}\text { Diuretics at discharge (\% from } \\
\text { discharged alive) }\end{array}$ & $302(49.5)$ \\
\hline $\begin{array}{l}\text { Blood Pressure at admission } \\
(\mathrm{mmHg}) \pm \mathrm{SD}\end{array}$ & $\begin{array}{l}130.2 \pm \\
22.9\end{array}$ & In-hospital stay (days $\pm S D$ ) & $5.6 \pm 4.2$ \\
\hline Triglycerides $(\mathrm{mmol} / \mathrm{L}) \pm \mathrm{SD}$ & $1.3 \pm 0.7$ & In- Hospital Mortality (\%) & $50(7.6)$ \\
\hline $\begin{array}{l}\text { GRACE score at admission } \pm \\
\text { SD }\end{array}$ & $\begin{array}{l}122.1 \pm \\
26.2\end{array}$ & & \\
\hline
\end{tabular}


Table 2

Compliance for ESC domains of quality for patients with AMI

$\begin{array}{llll}\text { Population } & \begin{array}{l}\text { Eligible } \\ \text { population }\end{array} & \begin{array}{l}\text { Availability } \\ (\%)\end{array} & \begin{array}{l}\text { Compliance } \\ (\%) S E\end{array}\end{array}$

1. Centre organization and system level Presented in section "Results" structures of AMI care

2. Reperfusion strategy

$\begin{array}{llll} & & & 40.6 \% \\ 475 & 390 & 370 & 268(72.4)\end{array}$

2.1 Proportion of patients with STEMI

475

390

$268(72.4)$

reperfusion therapy

2.2 For patients treated with fibrinolysis:

$<30$ min from diagnosis to the needle

3. In-hospital risk assessment

475

268

268

$43(16 \%)$

3.1 Proportion of patients having LVEF assessed before discharge

3.2 Proportion of patients with NSTEMI who have ischemic risk assessment using 185

660

660

$100 \%$

GRACE risk score

3.3. Proportion of patients admitted with

STEMI or NSTEMI bleeding risk

660

660

$660(100)$

assessment using

CRUSADE

4. In-hospital antithrombotic drugs

$98.1 \%$

4.1. Number of patients eligible for inhospital antithrombotic therapies who 185

185

$185(100)$

received $\geq 1$ therapy.

4.2. Dual antiplatelet therapy

660

648

638

$636(98.1)$

5. Secondary prevention discharge treatment

5.1 Proportion of patients with AMI discharged on statins, unless

660

655

645

$645(100)$

contraindicated

5.2 Proportion of patients with LVEF equal

610

94

610

610

$597(97.9)$

or less to $40 \%$ or clinical evidence of heart

failure, with betablocker prescribed at

discharge

5.3 Proportion of patients with LVEF equal or less to $40 \%$ or clinical evidence of heart

610

94

91

$87(92.5)$

failure, with ACE inhibitor prescribed at

discharge 


\begin{tabular}{|c|c|c|c|c|}
\hline & Population & $\begin{array}{l}\text { Eligible } \\
\text { population }\end{array}$ & $\begin{array}{l}\text { Availability } \\
(\%)\end{array}$ & $\begin{array}{l}\text { Compliance } \\
\text { (\%) SE }\end{array}$ \\
\hline $\begin{array}{l}\text { 5.4 Proportion of patients with smoking } \\
\text { cessation advice at discharge }\end{array}$ & 610 & 313 & 313 & $282(90.1)$ \\
\hline $\begin{array}{l}5.5 \text { Proportion of patients enrolled in } \\
\text { secondary prevention programs }\end{array}$ & 610 & 468 & 468 & $163(34.8)$ \\
\hline $\begin{array}{l}\text { 6. Patient experience collected in a } \\
\text { systematic way }\end{array}$ & \multicolumn{4}{|c|}{ Presented in section "Results" } \\
\hline \multicolumn{5}{|l|}{ 7. Outcome measures } \\
\hline In-hospital mortality rate & 660 & 660 & 660 & $50(7.6)$ \\
\hline 30-day adjusted readmission rate & 610 & 610 & 610 & $4(0.7)$ \\
\hline \multicolumn{5}{|l|}{ 8. Composite quality indicator } \\
\hline $\begin{array}{l}\text { Proportion of patients with LVEF equal or } \\
\text { less to } 40 \% \text { or clinical evidence of heart } \\
\text { failure, with DAPT and statins prescribed at } \\
\text { discharge }\end{array}$ & 610 & 92 & 92 & $85(92.4)$ \\
\hline $\begin{array}{l}\text { Proportion of patients with LVEF equal or } \\
\text { less to } 40 \% \text { or clinical evidence of heart } \\
\text { failure, with betablocker, ACE-I, DAPT, and } \\
\text { statins prescribed at discharge }\end{array}$ & 610 & 92 & 89 & $79(85.9)$ \\
\hline
\end{tabular}

\section{Evaluation of quality of care according domains}

- Domain 1: Centre organization and system level structures of AMI care. An internal protocol exists which asserts that every patient with STEMI and no contraindications to receive thrombolytic therapy, which symptoms started before $12 \mathrm{~h}$ should receive it.

In this center (as in Cuba), thrombolysis with Recombinant Streptokinase (Heberkinase, CIGB, Cuba) is standard therapy in patients with STEMI.

Patients can be assisted wherever they decide. There are 23 clinics, and 4 general hospitals (and among them, there is the General Hospital Camilo Cienfuegos, which is the leader of the Cardiology network), to assist a population of 466000 inhabitants around $6744 \mathrm{~km}^{2}$. Management of AMI can be done everywhere, however, diagnosis of NSTEMI, can be done only in the General Hospital. No cardiac biomarkers are available in other medical facilities.

Though no number of phone contact exist for patient with chest pain, emergency system can be activated by this way, by attending physicians or by patients. According to symptoms, an electrocardiogram can be done, which is widely available in the district. Though no practiced, there are several attempts to perform a trans-telephonic evaluation of electrocardiograms, to supervise treatment. If STEMI is diagnosed, patient transfer to proper setting in time, is attempted. However, as it usually takes 
more time than suggested (low number of available suitable vehicles), most patients, arrived by themselves. (Air transfer is not available in Cuba).

Since 2014 , time of attention are routinely recorded for this network, and periodical audits for quality assessment are often made.

- Domain 2: Reperfusion strategy. As stated, almost no patient was transferred to interventional setting (though patients with mechanical complications that require surgical treatment may be transferred). For NSTEMI, basis of treatment consists on pain management, and avoidance of other complications.

Median time for first medical contact was $319 \pm 300 \mathrm{~min}$, and delay system was $88.9 \pm 61.1 \mathrm{~min}$. As several patients with STEMI arrived with more than 12 hours since symptoms started $(17.7 \%)$, they usually, don't receive thrombolytics.

From those patients with indication who arrived in proper time, only received thrombolytic $72.4 \%$, and barely in 30 patients, electrical signs of reperfusion were observed. This may condition other QI which will be discussed, such as rate of complications, and in-hospital mortality.

- Domain 3: In-hospital risk assessment. One of the advantages of the designed electronic AMI registry is that, parameters to calculate risk stratification tools, such as TIMI, GRACE, and CRUSADE are of mandatory inclusion. So, the system itself, determine the score and send a warning message if one of these parameters is missing.

Besides, in hand-written reception of patients, is mandatory to determine them. Mean GRACE score was 112 (IQ: 18.5), CRUSADE score was 37.2 (IQ: 10), and TIMI score was 1.7 (IQ: 1.1), which means that most patients admitted in this center had a low or intermediate risk of death of major complications, which is not a reflex of the reality of those parameters.

- Domain 4: In-hospital antithrombotic drugs. Tough antiplatelets drugs as aspirin and heparins, are available, the only $\mathrm{P}_{2} \mathrm{Y}_{12}$ inhibitor offered in Cuba is Clopidogrel. Antiplatelet treatment is administered in most patients with AMI, reaching a very good $97 \%$ of double antiplatelet treatment administration. This fraction increases until an excellent $99.7 \%$, when patient which can't receive it due to several cases, were excluded.

Domain 5: Secondary prevention discharge treatment. Pharmacologic secondary prevention is widely administered. However, there is gap in the integration to secondary prevention programs. In our district, formally cardiac rehab (in a proper gym) is only offered in the gym of this hospital.

That's why, constrained inclusion criteria, need to be applied in order to offer this, to those who can beneficiate the most. However, suggestions to start to perform physical activity, and working restoration are carefully given to every patient and their relatives, before their fully discharge. 
Domain 6: Patient experience collected in a systematic way. Despite being a QI, patients and relatives experience is not routinely gathered. However, the service often receives tokens of appreciation from most patients and relatives, some of them in social media, radio, and TV reportages. Yet, from May 2020 on, this parameter will be recorded in the digital system. In Public Relations Bureau, there are only 4 complaints, all of them related to our crowded wait list for several exams that take place out of this center.

Domain 7: Outcome measures. After an update of protocols in summer of 2016, a consult to assist discharged patients with AMI was created. However, the coordination necessary to include data of this consultation and those responsible for entry them in the software, has not been implemented. So, statistics of patients at 30 day after discharge are lacking. Efforts to update this issue are currently running, and perhaps, in a near future, this indicator could be formally presented.

Despite this, in-hospital mortality is quite high: $7.6 \%$, which is a reflex of several gaps previously described.

Domain 8: Composite quality indicator. There is still an opportunity to increase the quality of treatment of those patients complicated with heart failure. Although a near- $90 \%$, is a good number, taking into account, that these patients didn't receive proper thrombolytic in time, will not have the chance of a coronary intervention in a near future, and their chance to have a proper cardiac rehab are very low, at least they should leave the facility, with an optimized medical management. So, improve is mandatory in order to extent the 1-year surviving rate of these patients.

\section{Discussion}

This study provides a continuous evaluation of quality of AMI care in a patient centered outcome from in LMIS, a non-interventional center, with free of charge and universal access to state funded-health care system. Comparison will be made with registries from LMIS, giving priority, for those reports coming from a network where most patients are treated with thrombolytic instead primary percutaneous coronary intervention, as possible.

Delgado-Acosta et $\mathrm{al}^{7}$. applied a survey from National Center of Epidemiology, in Cienfuegos $(110 \mathrm{~km}$ western of this center), in one month in 2013. They described a thrombolytic rate application of $72 \%$, (16/22), which may be considered very high. Prescription of betablockers in admission, were not as high, just $63.7 \%$. No data about ACE-I was recorded, and system delay was considerably lower compared with previous report in 2011. Despite these gaps, more than $92 \%$ of patients perceived the attention as good or better.

By the other hand, Lóriga-García et al.'s registry of AMI, in Pinar del Rio (most western district, 441 northwestern of this center), gives another result ${ }^{11}$. Of 644 patients admitted during 2011 and 2012 with STEMI, only 55,2\% received thrombolytic, $96.4 \%$ aspirin, $49.3 \%$ atenolol, and $32.9 \%$ ACE-I, lower frequency than Delgado Acosta et al for all drugs. And, 50 (7.7\%) patients died during hospital admission. 
In General Hospital Camilo Cienfuegos of Sancti-Spirítus, in 251 patients with STEMI, during 2014-2016, thrombolytic were administered to $57 \%$; betablockers, to $42.8 \%$; ACE-I, to $95.2 \%$; and statins to $94.82 \%$. System delay was $112.7 \pm 77.8 \mathrm{~min}$ and time from symptoms onset to needle was $354.5 \pm 266.4 \mathrm{~min}$ in those who received thrombolytic. Mortality was very high, even for LMISs: $13.5 \%{ }^{12}$.

Finally, there are the results of the REgistro CUbano de Infarto Agudo de Miocardio, where data of patients included in this report, are reported on it too. In order to perform an accurate analysis, common patients were excluded from this comparison. So, excluding data from General Hospital Camilo Cienfuegos, there were 638 patients remaining, of them 550 with STEMI, with a thrombolytic rate of $54.7 \%(301 / 550)$; Aspirin, Clopidogrel, Betablockers, ACE-I, and statin administration rate at admission of $97.2 \%, 99.1 \%$, $58 \%, 79.2 \%$, and $97.2 \%$ respectively. Mortality was $9.6 \%$, system-to-needle time was $49.9 \pm 47.1 \mathrm{~min}$; and $85.7 \%$ of patients which received thrombolytic system delay time was shorter than $60 \min ^{13}$.

Since introduction of Estreptoquinase no major change has been produced to reperfuse STEMI in last 20 years (coronary intervention is only available in 5 hospitals in Cuba) ${ }^{14-16}$. Beyond economic burden, there are external political situations that may impact on it. However, with same resources, several improvements are presented, when comparing with older reports from the same center.

Rest of pharmacological treatment is highly fulfilled at top level centers in Europe and United States, except perhaps, for betablockers. However, result shown in Cuban studies, are for overall population. And guidelines are clear: "Oral treatment with beta-blockers is indicated in patients with heart failure $<40 \%$ unless contraindicated (Class I, Level of Evidence A)" ${ }^{\prime \prime}$. When only patients with heart failure with blood pressure over $90 \mathrm{mmHg}$ in General Hospital Camilo Cienfuegos are included, this rate, in first 24 hours increases up to $93.1 \%(54 / 58)$, but decreases until $85 \%(45 / 53)$ in patients discharged alive. This analysis was impossible to make for another published papers due to lack of necessary data.

In our area, in Trinidad and Tobago, in a similar setting ${ }^{17}, 70 \%$ of women and $69.2 \%$ of men who received thrombolytic (70.5\% of overall population with STEMI), received it within first hour after first medical contact. Just $30.3 \%$ of patients received betablockers within first day of admission, but this, increased up to $76.5 \%$ at discharge. Rest of drugs, such as, aspirin, Clopidogrel, ACE-I, and statins were administered at discharge to $79.8 \%, 79 \%, 70.6 \%$, and $75.3 \%$, respectively.

In the Caribbean too, in Barbados, results like found in this report, were only achievable in male, in a specific group of age. Women were undertreated, as well as elderly, at their admission, as well with their discharge treatment ${ }^{18}$.

Data of the RENASCA, from 177 hospitals in Mexico during March 1, 2014 to December 2017, shows that $71.39 \%$ of patients, after implantation of "Infarction Code", received reperfusion of any kind, $40.1 \%$ with fibrinolytic therapy and $31.3 \%$ with Primary PCl. Commonly used drugs couldn't reach $90 \%$ of administration, and most of them were reduced during in-hospital stay ${ }^{19}$. 
The ACCESS registry showed that treatment in Latin America is quite suboptimal, although high rate of reperfusion by any means were reported. However, as barriers to adopt a guideline recommended treatment are common as well, quality improvement initiatives may work as well everywhere, despite the place where they were designed ${ }^{20}$.

In Africa, results are even more heterogeneous. However, three patterns may be described. First, in northern, attention seems to be dependent on patient's time for first medical contact, as technologies and human resources appear to be available $e^{21-23}$. Second, in sub-Saharan countries, attention looks to be really poor, based on absence of reperfusion treatment for most of patients, despite their delay time to seek for attention: few patients received thrombolytic, and a huge variation of system delay was observed, Betablockers and ACE-I administration didn't reach a quarter of available population ${ }^{24-26}$. And finally, in southern more-wealthy countries, attention seems to be the best of the continent, as stated by their higher fraction of patients with reperfusion, and secondary prevention treatments ${ }^{27}$.

Translating into practice

The absence of official document or consensus, about quality of attention of AMI in Cuba, make reports about it, heterogeneous, and hard to compare each other. However, some QI are universal despite conditions of network. Efforts from physicians to increase value of care should be directed, precisely, to those universal ones: rate of reperfusion, in-hospital and discharge treatment, and patient experience.

However, basis of networks is known by policy makers. And, as economic conditions are unlikely to change, it seems that the cheapest and short-term most effective way to increase quality of attention is by monitoring its markers.

Generate specific guide lines according to the real possibilities in the local setting where they are going to be applied is a right step but, even when some resources may be unavailable, there is no reason for excluding them. One must consider when and where those technologies can be introduced. In first place this is an opportunity to continue improving local protocols, and second this will contribute to do proper comparisons with higher standards, thus acute cardiac care physicians from LMISs most not consider the quality metrics from high income countries as unachievable, because then the continuous battle for improving care will be lost before it's started.

\section{Limitations of the study}

This study was made in a single center of Middle-Region in Cuba, an underdeveloped country with free of charge universal access to state funded-health care, which is not common in this kind of settings. Also, lack of coronary intervention, made its results hard to generalize for stings where this is present. Finally, this registry can't be considered as representative for the national population until specific analysis have made. 
However, its methodology may be considered as start point for futures evaluation of quality metrics, or descriptions of them.

\section{Conclusion}

Determination of the quality metrics brought some improvement for the perception of the actual quality of care. The difficulties to achieve high quality attention to these patients were common to those found in LMICs. Though important, patient-reported set of measures were not the cornerstone of these measures. Pre-hospital quality markers need to be improved, before trying to introduce a higher level of treatment.

\section{Abbreviations}

- LMISs: Low and middle-income scenario

- AMl: Acute Myocardial Infarction

- Qls: quality indicators

- STEMI: ST-elevation myocardial infarction

- NSTEMI: non-ST-elevation myocardial infarction

- GRACE: Global Registry of Acute Coronary Events

- TIMI: Thrombolysis In Myocardial Infarction

- ACE-l: Angiotensin Converter Enzyme Inhibitors

\section{Declarations}

Ethics approval and consent to participate

Ethical approval for the study was obtained from the Scientific Committee of General Hospital Camilo Cienfuegos, in its regular meeting on January 14th, 2020.

Consent to participate

as no personal data was gathered, nor presented in this manuscript, Consent to Participate was waived.

Consent for publication

Consent given.

Availability of data and materials

The datasets used and/or analyzed during the current study are available from the corresponding author on reasonable request.

Competing interests 
The authors declare that they have no competing interests.

Funding

Not applicable. no funding nor economic assist of any kind were received.

Authors' contributions

all authors have read and approved the manuscript.

- MARR: Concept/design, Statistics, Data analysis/interpretation, Approval of article, Responsible for the overall content as a guarantor.

- GCS: Drafting article, Critical revision of article, Approval of article.

- JAPM: Drafting article, Critical revision of article, Approval of article.

Acknowledgements

the authors would like to thank Miguel Rodriguez-Ramos would like to thank to all researchers from REgistro Cubano de Infarto de Miocardio Agudo.

\section{References}

1. Jia S, Liu Y, Yuan J. Evidence in Guidelines for Treatment of Coronary Artery Disease. Adv Exp Med Biol. 2020;1177:37-73. doi:10.1007/978-981-15-2517-9_2.

2. Shao C, Wang J, Tian J, Tang YD. Coronary Artery Disease: From Mechanism to Clinical Practice. Adv Exp Med Biol. 2020;1177:1-36. doi:10.1007/978-981-15-2517-9_1.

3. Pagan E, Chatenoud L, Rodriguez T, et al. Comparison of Trends in Mortality from Coronary Heart and Cerebrovascular Diseases in North and South America: 1980 to 2013. Am J Cardiol. 2017 Mar,15(6):862-71. doi:10.1016/j.amjcard.2016.11.040. 119) .

4. Ranasinghe WG, Beane A, Vithanage TDP, et al. Quality evaluation and future priorities for delivering acute myocardial infarction care in Sri Lanka. Heart. 2020 Apr,106(8):603-8. doi:10.1136/heartjnl2019-315396.

5. Tran DT, Welsh RC, Ohinmaa A, et al. Resource Use and Burden of Hospitalization, Outpatient, Physician, and Drug Costs in Short- and Long-term Care After Acute Myocardial Infarction. Can J Cardiol. 2018 Oct;34(10):1298-306. doi:10.1016/j.cjca.2018.05.022.

6. Domínguez-Alonso E. Zacea E. El Sistema de Salud en Cuba. Salud Publica Mex. 2011;53(Suppl 2):s168-76.

7. Hilda María Delgado-Acosta HM, González-Orihuela PY, Monteagudo-Díaz S, et al.: Calidad de la atención médica a pacientes con infarto agudo del miocardio. Cienfuegos 2013. Rev. Finlay [online]. 2016 Jun;6, (1):3-11. Available: http://scielo.sld.cu/scielo.php?script=sci_abstract\&pid=S222124342016000100002. 
8. Rodriguez-Ramos MA. Increasing Quality of Secondary Prevention of Acute Myocardial Infarction by Using EHealth. High Blood Press Cardiovasc Prev. 2019 Feb;26(1):81-82. https://doi.org/10.1007/s40292-018-0294-8.

9. Ibanez B, James S, Agewall S, et al. 2017 ESC Guidelines for the management of acute myocardial infarction in patients presenting with ST-segment elevation: The Task Force for the management of acute myocardial infarction in patients presenting with ST-segment elevation of the European Society of Cardiology (ESC). Eur Heart J. 2018 Jan;39(2):119-77. doi:10.1093/eurheartj/ehx393.

10. Rodriguez-Ramos MA: Registro Nacional de Infarto Agudo de Miocardio: No es una utopía. Rev Cub Cardiol Cir Cardiovasc 2017; 23(3) Available: http://www.revcardiologia.sld.cu/index.php/revcardiologia/article/view/699/html_96.

11. Lóriga-García O, Pastrana-Román I, Quintero-Pérez W. Características clínico epidemiológicas de pacientes con infarto miocárdico agudo. Características clínico Epidemiológicas de pacientes con infarto miocárdico agudo. Rev Ciencias Médicas. 2013;17(6):37-50.

12. Rodríguez-Ramos MA. Muerte súbita cardiovascular intrahospitralaria e infarto agudo de miocardio con elevación de ST: Resultados de RESCUE. CorSalud 2017 Oct-Dic;9(4):255-262.

13. Santos-Medina M, Rodríguez-Ramos $M$, Prohias-Martínez J, et al.: REgistro CUbano de Infarto de Miocardio Agudo (RECUIMA), los primeros 1000 casos. Rev Cub Cardiol Cir Cardiovasc 2019; 25(3) Available: http://www.revcardiologia.sld.cu/index.php/revcardiologia/article/view/895/pdf.

14. Gutiérrez-Loyola A, Druyet-Castillo D, Oramas-Domínguez, et al. Infarto de Miocardio Agudo en Cuba. Situación actual. Rev Cub Med Int Emerg. 2010;9(1):1638-48.

15. Lázaro A, Hernández-Rodríguez LA, Valladares-Carvajal FJ, Coll-Muñoz Y. Terapia trombolítica en pacientes con infarto agudo de miocardio en Cienfuegos. Rev Finlay. 2014;4(1):29-39.

16. Rodríguez-Londres J, Quirós-Luis JJ, Castañeda-Rodríguez G, et al. Comportamiento de la letalidad hospitalaria en pacientes con infarto agudo de miocardio con el uso de terapias de reperfusión en 12 años de trabajo en la Unidad de Coronario Intensivo del Instituto de Cardiología de La Habana, Cuba. Rev Mex Cardiol. 2014;25(1):7-14.

17. Bahall $M$, Seemungal $T$, Khan $K$, et al.: Medical care of acute myocardial infarction patients in a resource limiting country, Trinidad: a cross-sectional retrospective study. BMC Health Serv Res. 2019 Jul 18;19(1):501. doi: 10.1186/s12913-019-4344-2.

18. 10.1136/bmjopen-2018-025977

Sobers N, Rose AMC, Samuels TA, et al.: Are there gender differences in acute management and secondary prevention of acute coronary syndromes in Barbados? A cohort study. BMJ Open. 2019 Jan 28;9(1):e025977. doi: 10.1136/bmjopen-2018-025977.

19. Borrayo-Sánchez G, Rosas-Peralta M, Ramírez-Arias E, et al. STEMI and NSTEMI: Real-world Study in Mexico (RENASCA). Arch Med Res. 2018 Nov;49(8):609-19. doi:10.1016/j.arcmed.2019.01.005.

20. Martínez-Sánchez C, Jerjes-Sánchez C, Carlos-Nicolau J, et al. Acute coronary syndromes in Latin America: lessons from the ACCESS registry. Rev Med Inst Mex Seguro Soc. 2016;54(6):726-37. 
21. Moustaghfir A, Haddak M, Mechmeche R. Management of acute coronary syndromes in Maghreb countries: The ACCESS (ACute Coronary Events - a multinational Survey of current management Strategies) registry. Arch Cardiovasc Dis. 2012 Nov;105(11):566-77.

doi:10.1016/j.acvd.2012.07.002.

22. Hattab FE, Radi FZ, Hara L, et al.: Infarctus du myocarde inférieur: première série marocaine, à propos de 103 cas. Pan Afr Med J. 2019 May 31;33:74. doi: 10.11604/pamj.2019.33.74.16047.

23. 10.1371/journal.pone.0207979

Addad F, Mahdhaoui A, Gouider J, et al.: Management of patients with acute ST-elevation myocardial infarction: Results of the FAST-MI Tunisia Registry. PLoS One. 2019 Feb 22;14(2):e0207979. doi: 10.1371/journal.pone.0207979. eCollection 2019.

24. Kaboré EG, Yameogo NV, Seghda A, et al. Evolution profiles of acute coronary syndromes and GRACE, TIMI and SRI risk scores in BurkinaFaso. A monocentric study of 111 patients. Ann de Cardiol Angéiolog. 2019;68:107-14.

25. 10.1186/s12872-019-1043-1

Yao H, Ekou A, Hadéou A, et al. Medium and long-term follow-up after ST-segment elevation myocardial infarction in a sub-Saharan Africa population: a prospective cohort study. BMC Cardiovasc Disord. 2019 Mar 20;19(1):65. doi: 10.1186/s12872-019-1043-1.

26. Bahiru E, Temu T, Gitura B, et al. Presentation, management and outcomes of coronary syndromes: a registry study from Kenyatta National Hospital in Nairobi, Kenya. Cardiovasc J Afr. 2018;29(4):22530. doi:10.5830/CVJA-2018-017.

27. Delport R. Appropriate strategies for South Africa for the management of acute myocardial infarction in patients presenting with ST-segment elevation. Cardiovasc J Afr. 2018 Jan/Feb;29(. 